This is the accepted pre-edited version. For the final version, please refer to The International Journal of Fashion Studies 


\title{
What is 'space' for dress? Theoretical considerations of a spatial turn for fashion studies
}

Anna-Mari Almila

\begin{abstract}
This paper seeks to contribute to the increasing body of fashion scholarship focussed on space. Along with a spatial turn in human and social sciences, it is increasingly recognised by fashion researchers that spaces and places of fashion matter - but it is less discussed how a theoretical framework could be created to explore these. I here consider a Lefebvrian spatial analysis. The approach suggested recognises that dress is fundamentally political, as is the space which it inhabits. Dressed bodies are subject to hegemonic ideologies, but individuals have the power to resist these, too. I consider some parameters of a spatialized fashion sociology and what benefits such an approach can bring for fashion scholarship more generally.

I content that dress should be understood as spatial practice, which in its turn it creates spaces and realities, too. Such a framing allows for analysis of various spaces dressed bodies move through, and of how garments operate in these. Furthermore, it allows for extending the analysis by following garments through their whole life cycle, exploring the different kinds of spaces they enter. Such an approach has the potential for overcoming some persistent biases inherent in fashion scholarship, which tends to focus more on the 'core' than the 'periphery' locations of fashion.
\end{abstract}

Keywords space, spatial practice, Lefebvre, fashion theory, gender, dress in space

\section{Introduction}

When you walk Via Gramsci northwards in the city of Brescia in northern Italy, you come to face a monumental post office building built during the Fascist regime. Antonio Gramsci, after whom the street is named, was a political thinker, scholar and communist activist who was imprisoned by the Fascist regime and eventually died as consequence. He himself pointed out that hegemony - political, intellectual and moral leadership and authority, which he was prone to critique and criticise - is embodied in street names (cited in Adams and Sydie 2002: 91), so the many streets named after him across the country seem a highly ambivalent tribute.

In December 2018, a graffiti had appeared on a wall in a corner of Via Gramsci. It featured an image of a yellow vest - a reference to the gilets jaunes protests that at that time had spread from France and become partly transnational - with the text 'FUTURE?' (Figure 1). As ambivalent as Via Gramsci itself is as a tribute to a political thinker highly critical of established regimes, the graffiti illustrated to me the complexities of garments, bodies, and built environments, and the complex histories of all of these. A work garment turned into a symbol of resistance. A demonstrating body in a public space transformed into a sign in another geographical location. Bodies moving through this other space, seemingly blind to the contradictions and ironies built into their environment. Bodies marked by fashion, but with the potential to turn into bodies of resistance. 


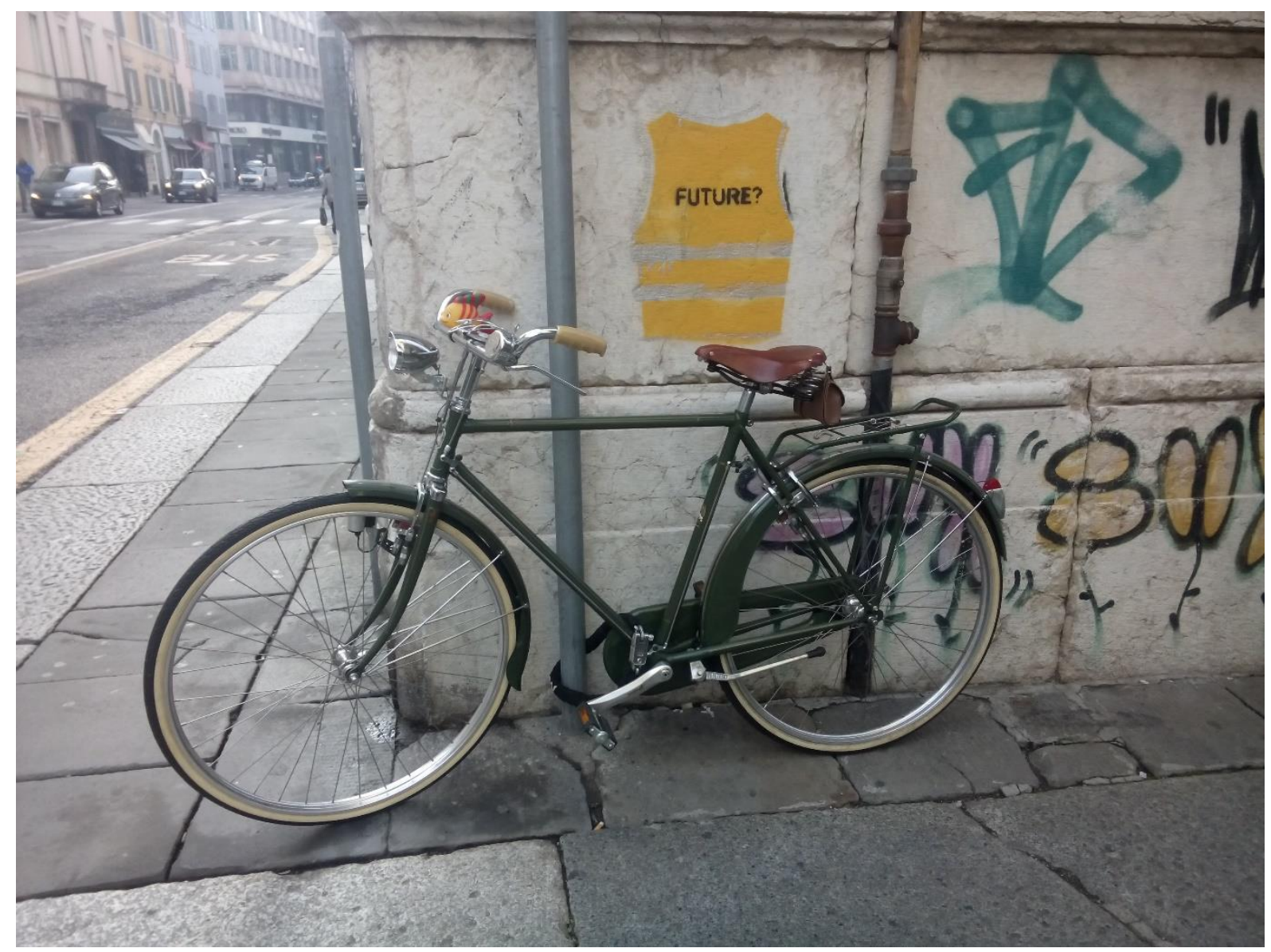

Figure 1. Photograph: author, 2018.

During the recent decade or so, an increasing interest in fashion as a spatial phenomenon has emerged. Thus, fashion handbooks, readers and source books increasingly feature a section on space (and/or place) (e.g. Black et al 2013; Bruzzi and Church Gibson 2013; Welters and Lillethun 2016), ${ }^{1}$ and books seeking to understand fashion as a system which is spatial, geographical and networked across distances have also been written (e.g. Potvin 2009; Crewe 2017). This goes together with a wider trend in human sciences. Soja (2010: 3) argued a decade ago that while 'the spatial turn' was 'still in its early stages', it was ongoingly rebalancing research focus towards recognising spatial dynamics and forces. But around the same time, Potvin $(2009,1)$ pointed out that 'discussions of space continue to be emptied of fashion [...] Likewise, spaces and places have often been overlooked in the writing of the visual and material cultures of fashion'. Responding to the call to take space more seriously in fashion studies, Rocamora (2013: 170) argued some years later that 'looking at the spatial formation of fashion means not only looking at its particular geography, as authors who have discussed fashion cities and related urban spaces have done [...] but also looking at the many "species of spaces" that it is made of, generates, or appropriates'.

We know that fashion cities are elaborately created (e.g. Rocamora 2009; Breward 2004; Gilbert 2006). We also know that spaces of fashion consumption and production are separated by ever-widening socio-geographical distances influenced by economic globalization (Aspers 2010). So too has the spreading of fashion changed through globalization, media and particularly the internet: '[a]t the beginning of the twentieth century fashion was largely diffused by means of direct observation. In order to see and learn what was in fashion [...] 
people had to observe each other [...] on the street, in cafés, and in other public spaces. Those who did not, or could not, visit these places had few means to really know what was in fashion and what was not', while anyone in possession of the necessary tools can access extremely current fashion at their leisure and pleasure today (Aspers 2013: 225). Beyond consumption and production, we know something about how everyday dress operates in specific city spaces, allowing, facilitating or restraining entry to venues, buildings and districts (Secor 2002; Woodward 2007; Almila 2018a). But the spatial turn has so far been incomplete. It lacks elaboration as to what space means (or could mean) for fashion scholarship at theoretical and methodological levels.

Towards that end, I offer a framework which can be utilised for understanding dress as a fundamentally spatial practice. Entwistle (2000a: 335) hinted at this possibility in her definition of fashion as situated bodily practice, and in arguing that ' $[\mathrm{d}] \mathrm{ress}$ is always located spatially and temporally'. She used Goffman's (and to a minor degree, Merleau-Ponty's) ideas in developing her argument of micro-social significance of dress. The approach I develop here draws upon a different kind of understanding of space, and aims for a spatialized fashion sociology approach. I use Henri Lefebvre's (1991[1974]) theory of space as a triad to demonstrate what kinds of potential there can be in this kind of spatial analysis for understanding the operations of dress and fashion, which are thoroughly shaped by ideologies and politics. I first discuss dress through Lefebvre's three spatial realms: spatial practices, representations of space, and spaces of representation. I then consider the fundamental interconnectedness and globalized nature of these spaces, before briefly reflecting upon the methodological and other research implications of a spatial approach to dress. What I offer is by no means a comprehensive analysis. Rather, I seek to illuminate the potential of a Lefebvrian spatial understanding for fashion studies, and also to highlight the significance of dress for the operations of space.

\section{Dress as Spatial Practice}

According to Lefebvre (1991[1974]: 57), space pre-exists its actors, and 'conditions the subject's presence, action and discourse'; yet space is also produced by humans as they create and enact social relations, knowledges and institutions (Elden 2004: 184). For Lefebvre, space is simultaneously physical, mental and social. Physical space is the 'space that is generated and used', while mental space 'is the space of savoir (knowledge)' (Elden 2004: 190). Social space is a space that is lived, but it is also 'indistinguishable from mental space [...] and physical space' (Lefebvre 1991[1974]: 27). Lived social space is fundamentally influenced by, and intertwined with, mental and physical spaces. Space is a process functioning on various levels, produced by humans, and producing them. Lefebvre understands space as a triad: at the same time perceived, conceived and lived. The relationship between these realms is dialectical, meaning that these co-existing spaces are potentially oppositional, conflicted, transforming and transformative.

The first spatial realm is spatial practices, which Lefebvre (1991[1974]: 33) defines as embracing 'the particular locations and spatial sets characteristic of each social formation'. Spatial practices produce and reproduce space at an everyday level, in a manner that is usually cohesive. This is evidenced in individuals inhabiting particular social spaces tending to engage in similar spatial practices, such as wearing clothes deemed as 'appropriate' for the setting and 
situation. Spatial practices include all the everyday routines and patterns, which, while being practised and performed, also reveal how the space in question is perceived by the individuals inhabiting it. These practices involve events and occurrences in specific locations, which impose their sartorial and other rules and requirements upon individuals. For example, workwear often differs from dress we wear in spaces we perceive as places for leisure, for the workplace is perceived as a space for certain kinds of activities by the different kinds of individuals who participate in those activities.

In this sense, spatial practices are hegemonic (Gramsci 1971), for they are typically shaped and determined by powerful social groups, routinized, and generally go unquestioned by the people who engage in them. We usually do not need long time to get dressed for work in the morning, as our dressing operates at the level of practical consciousness - neither fully conscious, nor fully unconscious. Habituation is a powerful force as it comes to everyday dress practices and comfort/discomfort experienced when wearing one's clothes (Rouse 2007[1989], Almila 2018b). And while dressing for a special event typically would require more effort and consideration, our recognition of the specific requirements of each type of space and situation is as keen and, usually, as accurate as in the case of more mundane everyday activities.

One key characteristic of dress is that it is deeply gendered, often in unquestioned ways (e.g. Barnes and Eicher 1992; Breward 1999; Burman and Turbin 2003; Evans and Thornton 1989; Lynch 1999). Likewise, human geographers are aware of the gendered nature of space (e.g. Ardener 1993; Hanson and Pratt 2005; Löw 2006; Massey 2013). This gendered nature of space goes beyond ideas of supposedly gendered characteristics of 'masculine' and 'feminine' architecture. Spaces are gendered because they are differently available (or not) for men and women, as well as for those of other genders. ${ }^{2}$

Spaces are also allowing different kinds of behaviour, including dress choices, for men and women: individuals' actions and motivations are evaluated differently depending on spaces they enter, the time of them doing so, and the dress they are wearing. Thus, a transgender woman may be legally banned from women's toilets, but she may nevertheless enter such a space without challenge depending on her appearance - when her dress and general appearance conform successfully to hegemonic spatial practices. And while there are in most countries no laws banning a woman walking home alone late at night, she may still be censored both socially and in terms of law if she is sexually assaulted under such conditions. Her choice of dress and lingerie may be subjected to humiliating commentary and used as proof against herself rather than her assaulter. In other words, she has engaged in a spatial practice condemned by normative patriarchal ideology. Shaped by deeply rooted patriarchal assumptions, the politics and geographies of fear (England and Simon 2010) are fundamentally intertwined not only with gender but also with dress.

Space is also gendered in less radical (yet potentially equally powerful) ways in terms of spaces for labour, leisure, schooling and education, and specific places such as children's playgrounds, pubs and coffee shops. Workplaces are marked through workwear, which is typically gendered in standardised ways (e.g. different coverage of legs, different shoes, different cuts and details, different colours for women and men). The business suit is a case in point. Symbolic today ${ }^{3}$ of the field of economy (as well as political power), the suit envelops, alters and constructs the male body (Hollander 1994), rendering it fitting with white-collar workplace environments. For the female body, the suit operates differently, both adapting the body by marking it 
'professional' and upholding and creating gender distinction considered necessary for social order in the workplace (Entwistle 1997; 2000b; Steele 1989).

Yet the servile position of many wearers of the suit is evident in the spaces the carrier of the suit must enter on way to work and back: stations, public transport (typically arranged following a logic whereby the built environment both steers bodies through the space and reveals the ideological principles behind capitalist 'rationalisation'), streets, shops. The business suit is a way of indicating one's occupation by separating the suit-clad body from, say, leisure-time bodies. Engagement with cultural consumption while wearing the business suit (such as going to the pub with colleagues after workday) is shaped by the suit, for the consuming body is visibly marked as belonging in the realm it labours for during the day. This same distinction is evident in how the suit-clad bodies move through public spaces: purposefully and with a quicker pace than leisure-focussed bodies. At the same time, these bodies construct city spaces - which can also be differently occupied and thus constructed - as operational parts of the field of economy. Space and dressed bodies co-create each other.

In another kind of environment, such as children's playground, bodies are typically female, dressed in a more leisurely manner and occupying space with a slower rhythm. To come to the playground wearing a business suit would indicate that one is on one's way to work (and thereby not fully engaged with one's offspring). This could potentially be risky behaviour especially for mothers, who struggle more than their male counterparts to balance parenthood and work life. But also 'overdressing' for the playground has its risks. It is often assumed that a 'good mother' makes sacrifices for the sake of her children, and thus may be expected to focus more on the child's clothing than on her own (Collett 2005). Thereby, also the playground emerges as a physical and ideological space that is fundamentally gendered through dress. The built environment itself does not gender space, it is the spatial practices and ideologies behind them that do so - and dress is an elementary part of such spatial practices.

\section{Representations of Space Directing Dress}

The second, and dominant, realm of space is representations of space: the realm of architects, urban planners, and engineers. It is a conceptualised space that has a practical impact. It is informed by ideologies and knowledges, and functions through construction, architecture, design and urban planning. For Lefebvre, ideology meant primarily political and economic systems of thought which have fundamental consequences to how urban environments are organised. Representations of space, he argues, are informed by hegemonic ideologies - such as capitalism as an economic system - and serve to reproduce and communicate them.

The difference of focus between spatial practices and representations of space is that the first largely operates with things in space (such as clothed bodies, and architectonic structures that determine how the bodies move through space and inhabit spaces), while the second tends to operate on thoughts about space: the first is physical/material while the second is mental and ideological (albeit with concrete results in the form of buildings and plans). This means that through the built environment people are made to operate in certain, ideologically influenced ways. Such ideologies involve the communication of desirable and undesirable activities. Through architecture, design and urban planning, impermissible activities (such as sleeping rough in public spaces) can be made impossible or difficult, so that officially banning such 
activities becomes unnecessary. But at the same time, such architecture communicates the desirability or undesirability of certain groups of individuals moving and living in certain spaces in specified manners (Nissen 2008). This, too, often goes uncontested and unchallenged, being hegemonic and consensual ${ }^{4}$ in character (Gramsci 1971). All too often, one's dress and appearance reveal - both intentionally and unintentionally - whether one fits the ideology of the built environment or not, whether one is desirable in the environment or not. This is the basis of some individuals becoming more or less visible in spaces according to their visual 'fit' (Almila 2018b). Certain kinds of garments fit with certain kinds of architecture and spatial organisation.

For example, 'architecture of transparency' as a general architectural trend emerged in the early twentieth century. Ideologically, it was assumed to represent openness, honesty and accountability (Whiteley 2003). Philosophically speaking, transparency refers to 'the ability of the light of the mind to pass through a concept so that its true nature, or hidden essence, is perceptible' (Ascher-Barnstone 2003: 3). This assumes both that there is a hidden essence and that that essence needs to be revealed. In other words, transparency operates on the assumption that hiding something is dishonest and suspicious, and therefore to reveal what is hidden is legitimate. In such architecture, the ideology is precisely this: the state has the right to reveal individuals' (supposed) secrets. The spatial practice enabled through such architecture is constant surveillance. And a possibility of resistance is also there, in the form of garment choices. Some of these are typically considered more legitimate - surgical masks, respirators, helmets, sunglasses, carnival masks - and others are made less legitimate through thoroughly ideological and power-driven discourses: hoodies, face veils (Inglis 2017; Kinney 2016; Moors 2009; Pearson 2006).

But face veils that would look 'foreign' or 'unfitting' in representations of spaces where the guiding principle is transparency, look different in spaces that follow the same logic as veiling, namely gender segregation. According to Janet Abu-Lughod (1987), in what she calls the typical 'Islamic city' - meaning a city built according to Islamic architectonic tradition - it has traditionally been the case that each neighbourhood was built as separate from others, with only one entrance to the courtyard from outside. This created a semi-private space, guarded by a gatekeeper, whose duty it was to alert the inhabitants to the approach of a stranger. This allowed for relative relaxation of (female) dress rules when no one but the neighbours could see. Such representation of space creates a specific environment, which is in balance with certain kinds of spatial practices, including dress.

Neighbourhoods may still today have specific characteristics in terms of dress. For example, in Istanbul, certain areas of the city are difficult or impossible to enter for those women who veil, while others are out of bounds for those who do not veil (Secor 2002). These respective parts of the city are different kinds of environments, creating and enabling certain kinds of spatial practices, and rejecting others. Politics of visibility are central to such experiences: that which is considered non-normative is made visible through its very difference (hooks 2003; Tarlo 2010; Almila 2018a). This is a difference from not only the other bodies in the spaces, but also from the expectations built in into the environment.

Altogether different from such spaces of wearing garments are the spaces of making garments (although the makers wear garments, too). The production and supply chain form extremely complex networks across locations, and its functions are often hidden behind neutral facades 
(Hagemann 2015). Indeed, it is typical for fashion systems that some fashion spaces are visible, and in the limelight, while others are purposefully hidden (Blaszczyk 2013; see also Crewe 2017; Breward 2006). The most dominant principle in garment production is the capitalist ideal of 'efficiency' and 'rationalisation', and the production spaces are typically arranged accordingly. Needless to say, these spaces can be extremely hazardous for those who labour within them, when the ideology that defines the representations of space aims at financial profit rather than the wellbeing of individuals.

The spaces many fashion scholars speak of tend to be urban, and often located at the cores of the global fashion system. But other places matter, too, and those places have their spaces. As de Certeau (1985: 127) has argued, wealthy city spaces operate on the principle of 'rejection of whatever is not treatable, and that thus constitutes the "garbage" of a functionalist administration (abnormality, deviance, sickness, death, etc.)'. But the rejection also extends to the exclusion of spaces of production, including the 'back stages' of fashion (Crewe 2017). This exclusion works hand in hand with the creation of myths: 'rationalizing the city involves mythifying it through strategic modes of discourse' (de Certeau 1985: 127, emphasis in original). Fashion myths are particularly powerful in this regard, creating forms of privilege for the established global fashion cities: Paris, London, New York, Tokyo, Milan.

Such mythifying has more recently extended also to virtual spaces (Rocamora in press). For example, la Parisienne lives today beyond city spaces and print media. It is the property of online social media platforms: \#parisienne imagery - which uses Paris as griffe spatiale, spatial (design) label (Pinçon and Pinçon-Charlot in Rocamora in press) - formulates both spaces and bodies that are considered normative in fashion discourses. It is therefore important to remember that discourses shape our knowledge of both spaces and garments, and those discourses happen in many venues today, including deterritorial, virtual ones. These are shaped by, and also come to shape, representations of spaces at ideological level, creating knowledge as to how a specific urban location is to be understood and what would be appropriate dress in that context.

\section{Spaces of Representation Enabling Dress Resistance}

The third realm of space, spaces of representation (or representational spaces), ${ }^{5}$ is dominated in character. These are symbolic spaces lived, imagined and narrated by their users. They allow for resistance - they are spaces that 'imagination seeks to change and appropriate' (Lefebvre 1991[1974]: 39). Consequently, they are both hegemonic (due to representations of space and spatial practices having hegemonic influences on them), and potentially counter-hegemonic that is, resistant to, or critical of, hegemonic ideas - since the lived space allows for creativity, variety and resistance. These are alternative spaces, created often by people who seek to imagine life differently from the norm. A fashion designer who seeks to imagine fashion (and thereby the world) differently is therefore operating in spaces of representation. And through such imaginings, counter-hegemonic realities can be created, not only by designers, but also by individuals who wear garments that tell alternative narratives about alternative spaces and realities.

For example, feminist resistance challenging patriarchal structures takes place both in the form of large movements, such as SlutWalk (Lim and Fanghanel 2013), and activist groups, such as 
Femen and Pussy Riot. These take advantage of the very structures that determine spaces (and sometimes in patriarchal order work against them): citizen's right ${ }^{6}$ to enter public spaces, and for political participation. These are also fundamentally gendered movements and groups focussed on dress: woman's right to walk unharassed irrespective of dress choices on the one hand, and using nudity, masked faces and highly provocative dress for political purposes on the other. They seek to use and imagine (public) spaces differently from patriarchal ideology, and therefore their attire (or lack thereof) operates in spaces of representation.

There are less radical forms of resistance, too. For example, dress guards the limits of privacy, an individual's decision power over their own body and its coverage (Masquelier 2005). While space is often spoken of in terms of 'public' and 'private', dress might be understood in terms of intimacy and familiarity between the users of space (Goffman's (1990[1959]) front/backstage conceptualisation is an example of this). Private and public are more fluid than would appear when discussing only the supposed character of certain built environments (Abraham 2017; Almila 2017). Instead, individuals may to a certain extent be in charge of the levels of privacy they achieve in different spaces. Here, again, dress operates to manage spaces, and to create them at the same time. A temporary space of intimacy can be created around friends or lovers, whereby bodies touching each other communicate belonging, a unit. Bodies can be much more closely cramped together in public transport during the rush hour without any intimacy. In each of these scenarios, how clothing is worn and how bodies touch each other create spaces that are either intimate or simply shared.

Garments also manage the gaze of others (Almila 2018a). How much of our bodies (skin and/or shapes) we want to expose to the gaze of others is primarily managed by clothes: wearing a jacket at workplace to avoid sexualised gaze on one's breasts (Entwistle 2000b), wearing 'modest' dress for religious or other reasons (Lewis 2013), seeking to blend in in one's environment through dress choices (already Simmel (1904) argued that this is one of fashion's functions). Yet there are forms of gaze that an individual is not necessarily allowed to manage: those sanctioned and/or managed by the state. These forms of gaze are impersonal, and all the more powerful for that (Foucault 1977).

Increasingly, a demand for 'openness' is part of the built environments today. 'Transparent' architecture, CCTV, body searches and body scans are all part of an environment of 'security' whereby bodies are subjected to anonymised surveillance and governance by the state for the sake of 'safety' (Magnet and Rodgers 2012). Whether the explicit target is those covering their faces in a certain manner (such as 'Islamic' face veils - Brems 2014) or those wearing certain kinds of headwear (such as hoodies - Kinney 2016; Pearson 2006), such surveillance is supposed to be objective and impersonal. In reality, it reveals worrying structures whereby those perceived to have a lower social standing, or those with non-normative bodies, are more of a target than those with wealth and power (Almila 2018a; Magnet and Rodgers 2012).

But through garments, individuals can imagine alternative spaces: spaces of representation, where anti-CCTV design, face veils and hoodies are sources of empowerment, ways of critiquing the hegemonic social order (Almila 2018a; Crewe 2010; 2017). Or, alternatively, individuals might choose to wear a surgical mask instead of a face veil as a means of continuing (through adaptation) one's preferred dress custom despite legislative regulations - a disparity pointed out in many anti-ban protests (and ever more striking since Covid-19). This would be less of a strategy to imagine alternative spaces than it is making use of normative spatial 
practices while upholding one's ideals of privacy in public, whereas wearing the mask in an anti-ban protest is an open resistance to perceived legislative unfairness and normative ideology. These distinctions are important, for they show how all three types of spaces can coexist, even in one individual's dress choices. Indeed, while dress is, fundamentally, a spatial practice, it is also very much operating in spaces of representation, too.

\section{Interconnections and Global Connections}

Lefebvre's ambition when introducing the model of space as a triad was to go beyond dualisms he saw as shaping social thought in undesirable manners. His model allows for many different kinds of actors and actions to be recognised and analysed as they operate in different but interconnected spaces. Spaces are conceived (representations of space), lived (spaces of representation) and perceived (spatial practices). These different realms are 'interconnected, [such] that the "subject" [...] may move from one to another without confusion' (Lefebvre 1991[1974]: 40). Ultimately this means that both hegemonic and counter-hegemonic spatial elements co-exist at the same time, which enables new kinds of realities to emerge and be integrated trough the dialectics of space. However much hegemonic power structures seek to determine the world, it is possible for groups and individuals to imagine spaces differently. For example, spaces can be designed to be inclusive, enabling more equal social and political participation (Nissen 2008).

Arguably, spatial realities can spread today with extreme rabidity and come to be deterritorial - not bound to any particular territory/ies - in character. Yet space is always contextual, for 'space and time do not exist universally. As they are socially produced, they can only be understood in the context of a specific society' (Schmid 2008: 29). This is what, fundamentally, gives meaning to places and locations, too. In other words, space is produced over a course of location-specific history - although this is not to say that there would not be transnational, transregional and other non-local cross-influences. Space must be understood as a history that is both formulated by, and itself formulates, the very social history of the particular location and beyond. Consequently, understanding space 'calls for an analysis that would include the social constellations, power relations, and conflicts relevant in each situation' (Schmid 2008: 29). As discussed above, dress is an elementary part of such struggles and structures. Dress both is shaped by these conditions, and reproduces and transforms social realities.

It is worth mentioning here that Edward Soja, who was strongly influenced by Lefebvre, pushed these notions towards slightly different direction. In his famous definition of the 'thirdspace', he states that this is 'a fully lived space, a simultaneously real-and-imagined, actual-and-virtual locus of structured individuality and collective experience and agency' (1996: 11). It was his contention that in the analytical triangle of the social, the historical, and the spatial, no realm should be considered more important that the others, but all should instead be analysed together (Soja 2010).

In light of this, I wish to stress the importance of socio-historical-spatial analyses of dress and fashion practices. Space can be used to control bodies and their representations, but bodies also create and re-create space. Lefebvre states that 'each living body is space and has its space: it produces itself in space and it also produces that space' (1991[1974]: 170, emphasis in original). ${ }^{7}$ According to de Certeau (1985: 129), 'spatial usage creates the determining 
conditions of social life'. In this kind of a frame, all embodied activities must be analysed with reference to material space, spatial structures, and spatial perceptions. Furthermore, dress practices (and how they are perceived) are either in consensus with the dominant representations of space (e.g. architecture) and spatial practices (e.g. normative dress), or they will be imagining, explicitly or implicitly, an alternative spatial existence in relation to what is dominant. For example, it is well known that the fascist regimes of Germany and Italy considered architecture, urban planning and dress all crucial for the establishment of their ideology and rule (Paulicelli 2004; Speer 1969). Likewise in the Soviet bloc, both space and fashion (as well as other art forms) operated in terms, and in service, of political and economic ideology (Bartlett 2010; Dobrenko and Naiman 2003). And in a time of increasing, often intrusive, surveillance, it is possible to imagine alternative ways of existing through anti-CCTV textiles and garments (Crewe 2010; 2017).

Spaces can also be considered as produced by and for specific fields (Rocamora 2013). For example, the powerful fields of politics and economy are often strongly present in representation of spaces. Bourdieu (1985) considered social space as a kind of summary of all the fields an individual participates in - field here meaning the relations of power that individuals operating in these fields are embedded in. Such social space is not necessarily about the built environment, nor is it fully defined by geography. Yet fields create spaces and environments. For example, the fields of state politics are located in buildings indicating power and centrality to the nation. In centres of economic power, both architecture and location communicate central status. A fashion event may be constructed in a manner whereby the physical location of an individual in comparison to others embodies the position the individual holds in the field of fashion (Entwistle and Rocamora 2006). A garment retail shop can be understood as a space where the field of economy and field of fashion come together (Rocamora 2013). Understanding social space as a realm of social locations, dependent on an individual's locations in multiple fields, helps us to link local spaces with globalized spaces characteristic of fashion systems today. While power and ideology are embedded in geographical locations and built environments, they also bind individuals beyond such physical locations. Hierarchical distance between individuals draw a map of social belongings beyond geographical locations, whether those individuals operate in garment production or are (privileged) wearers of said garments.

\section{Implications for a Spatialized Fashion Sociology}

The obvious question following from the above discussion would be its implications as to how dress phenomena should be researched? There is no straightforward answer to this in terms of applying certain universal methods or methodologies. Some suggestions can, however, be made. A Lefebvrian understanding of space stresses the co-existence and co-creation of spaces and bodies. When dress is added to this as a central category, it necessitates the exploration of the histories both of spaces and of garments. These should also be studied at micro- and macrolevels. What is crucial to use here is Kopytoff's (1986) notion of objects changing their nature during their life-course. I have argued elsewhere that garments change their character when moving between different kinds of spaces (Almila 2018a).

Lefebvrian analysis can add a great deal to dress and fashion analyses. Entwistle (2015) suggests that, in the spirit of Actor-Network Theory, there is a great potential for fashion 
scholarship in following garments through their production, distribution, consumption and recycling stages. The fashion system, within which large parts of dress production, distribution and consumption happens, spreads around the globe today. Yet simply to follow garments in order to see what happens to them would be of little use without an understanding of their spatial surroundings in each phase of their journey. I have here focussed largely on the everyday wearing of clothes, but this kind of Lefebvrian analysis could also be applied to different parts of the fashion system. It is easy to see that spaces of fashion production, distribution and consumption are largely organised according to capitalist logics. But as in any spaces, this is not the total extent of those spaces. The focus on different kinds of spaces, and the dressed bodies operating within them, can offer new kinds of openings for the purposes of analysing the complexities of fashion networks as these operate in and through spaces and locations within an increasingly complex globalized world. The globalized fashion system connects very different kinds of spaces. The interesting question to pose about these spaces is how garments operate in all of these spaces, and what they do to the people handling them, watching them, wearing them, as well as to the spaces themselves, which the garments travel through in complicated ways which need unpacking.

For a more micro-level, everyday study of dress, Lefebvrian spatial analysis can also open up new possibilities. For example, ethnographic observation and participant observation (Brewer 2000; Spradley 2016), as well as wardrobe interviews (Woodward 2007), are well established techniques in fashion scholarship. To analyse the relations between spaces and dress choices, methods from human geography (often already influenced by Lefebvre's thinking) can be used alongside more established methods, such as by mapping the gendered nature of spaces in terms of where people spend time, and where they avoid being (Ranade 2007), or by mapping and timing the usual walking and travelling routes of individuals, including the avoidance of some routes (Perkins 2016). This kind of methodological position is very much about paying attention to that which is not usually commented upon by people themselves. Just as individuals have tacit knowledge of certain socio-normative uses of space - or in Lefebvre's terms, tend to perform spatial practices in hegemonic ways - they also have sophisticated pragmatic knowledge about suitable types of dress for a wide range of social situations and the spaces that express and make possible those situations. Individuals are often highly sensitive to indicators of dress 'failure', when their outfit lets them down socially (Woodward 2007).

Understood in this light, the wardrobe emerges as a spatial object and category worthy of study in its own right, beyond matters of using wardrobes for reasons of mere methodological convenience. The wardrobe is a space of organised spatial practices, driven by rationalisation of domestic space (Cwerner 2001), that creates certain kinds of representations of space, and it is also a space of representation which individual and collective imaginations drive and shape. Just as any space is mental, physical and social at the same time, so too is the wardrobe both a physical space consisting of garments, and a mental and social space which an individual's wardrobe collecting practices construct and represent. A Lefebvrian extension of analysis of wardrobes puts the emphasis firmly on how they are spaces where different kinds of spatial realms meet, connecting the most intimate matters of personal taste and garment choice together with massive and globalized social forces.

\section{Conclusion}


A Lefebvrian analysis or dress/space relations would be thoroughly political in the widest sense of the word. After all, many of his key concepts are based upon a continuum of historicalpolitical analyses, theories and authors. Fashion and dress are, and have always been, political too. It is not neutral what we wear. It is not neutral how we gained the garments and who made them and how. To understand fashion systems as constellation of spaces and connections can help us see more clearly how dress is intertwined with the politics of its production, distribution, consumption, and wearing. The everyday lives of many kinds of actors are crucial for the understanding of how dress and fashion systems are globalized today. This is important because through this kind of analysis, it is possible also to shift focus towards more 'peripheral' spaces from those considered 'fashion centres' (see also Craik 1993). As noted by Said (1994), geographies are about struggles, and struggles are geographies - defined not only by economic or military forces, but also by 'ideas, forms, images, imaginings'. The discourses involved are as ideological as are the phenomenological spaces themselves. And they shape and construct our embodied experiences in the spaces we occupy in our everyday lives. This is precisely why spaces, ideas and dressed bodies must be seen in relation to each other. Dress is not only a situated practice; it is a spatial practice, shaped by powerful ideologies. And in its turn, it creates spaces and realities, too.

The ambitious project this paper proposes for fashion studies is to bring together different kinds of analyses and different fields of scholarship for the benefit of dress and fashion scholarship in a complex, globalized world. This is more than bridging studies of production and consumption. It is an approach seeking to look at both the journey of garments through chains of production, distribution, retail, consumption, wearing, recycling and discarding, and how the spaces that garments travel through, and bodies that operate in those spaces, co-create each other. Such a project is necessarily one that any individual researcher can only approach with limited means and resources: as all best research, it must be a collaborative process.

\section{References}

Abraham, J. (2017), 'Hindu and Muslim Veiling in North India: Beyond the Public/Private Dichotomy', in A. Almila and D. Inglis (eds), The Routledge International Handbook to Veils and Veiling Practices, London: Routledge, pp.246-54.

Abu-Lughod, J. (1987), 'The Islamic City--Historic Myth, Islamic Essence, and Contemporary Relevance', International Journal of Middle East Studies, 19:2,pp.155-176.

Adams, B.N. and Sydie, R.A. (2002) Contemporary Sociological Theory. London: Sage.

Almila, A. (2017), 'Veiling in Space: On the Fluidity of Public and Private', in A. Almila and D. Inglis (eds), The Routledge International Handbook to Veils and Veiling Practices, London: Routledge, pp.231-45.

Almila, A. (2018a), Veiling in Fashion: Space and the Hijab in Minority Communities, London: IB Tauris.

Almila, A. (2018b), 'The Dressed Body, Material and Technology: Rethinking the Hijab through Sartorial Sociology', International Journal of Fashion Studies, 5:2,pp.309-28.

Ardener, S. (ed.) (1993), Women and Space, London: Bloomsbury. 
Ascher-Barnstone, D. (2003), 'Transparency: A Brief Introduction', Journal of Architectural Education, 56:4,pp.3-5.

Aspers, P. (2010), Orderly Fashion: A Sociology of Markets, Princeton: Princeton University Press.

Aspers, P. (2013), 'Markets as Fashion Spaces', in S. Black, A. de la Haye, J. Entwistle, A. Rocamora, R.A. Root and H. Thomas (eds), Handbook of Fashion Studies, London: Bloomsbury, pp.224-35.

Barnes, R. and Eicher, J. (1992), Dress and gender: making and meaning in cultural contexts, Oxford: Berg.

Bartlett, D. (2010), FashionEast: The Spectre that Haunted Socialism, Massachusetts Institute of Technology.

Blaszczyk, R.L. (2013), 'The Hidden Spaces of Fashion Production', in S. Black, A. de la Haye, J. Entwistle, A. Rocamora, R.A. Root and H. Thomas (eds), Handbook of Fashion Studies, London: Bloomsbury, pp.192-206.

Bourdieu, P. (1985), 'The Social Space and the Genesis of Groups', Theory and Society, 14:6,pp.723-44.

Brems, E. (ed.) (2014), The Experiences of Face Veil Wearers in Europe and the Law, Cambridge: Cambridge University Press.

Breward, C. (1999), The hidden consumer: masculinities, fashion and city life 1860-1914, Manchester: Manchester University Press.

Breward, C. (2004), Fashioning London: Clothing and the Modern Metropolis, Oxford: Berg.

Breward, C. (2006), 'Fashion's Front and Back: 'Rag trade' Cultures and Cultures of Consumption in Post-war London c. 1945-1970', The London Journal, 31:1,pp.15-40.

Breward, C. and Gilbert, D. (eds) (2006), Fashion's World Cities, Oxford: Berg.

Brewer, J. (2000), Ethnography, Open University Press.

Bruzzi, S. and Church Gibson, P. (eds) (2001), Fashion Cultures: Theories, Explorations and Analysis, London: Routledge.

Bruzzi, S. and Church Gibson, P. (eds) (2013), Fashion Cultures Revisited: Theories, Explorations and Analysis, London: Routledge.

Burman, B. and Turbin, C. (eds) (2003), Material strategies: dress and gender in historical perspective, Oxford: Blackwell.

Craik, J. (1993), The Face of Fashion, London: Routledge.

Collett, J.L. (2005), 'What Kind of Mother Am I? Impression Management and the Social Construction of Motherhood', Symbolic Interaction, 28:3,pp.327-347.

Crewe, L. (2010), 'Wear:where? The convergent geographies of architecture and fashion', Environment and Planning A, 42,pp.2093-108. 
Crewe, L. (2017), The geographies of fashion: consumption, space, and value, London: Bloomsbury.

Cwerner S.B. (2001), 'Clothes at Rest: Elements for a Sociology of the Wardrobe', Fashion Theory, 5:1,pp.79-92.

de Certeau, M. (1985), 'Practices of Space', in M. Blonsky (ed.), Signs, Baltimore: Johns Hopkins University Press, pp.122-45.

Dobrenko, E. and Naiman, E. (eds) (2003) The Landscape of Stalinism: The Art and Ideology of Soviet Space, Seattle: University of Washington Press.

Elden, S. (2004), Understanding Henri Lefebvre: Theory and the Possible, London: Continuum.

England, M.R. and Simon, S. (2010), 'Scary cities: urban geographies of fear, difference and belonging', Social \& Cultural Geography, 11:3,pp.201-207.

Entwistle, J. (1997), "'Power Dressing" and the Construction of the Career Woman', in M. Nava, A. Blake, I. MacRury and B. Richards (eds), Buy This Book, London: Routledge, pp.311323.

Entwistle, J. (2000a), 'Fashion and the Fleshy Body: Dress as Embodied Practice', Fashion Theory, 4:3,pp.323-48.

Entwistle, J. (2000b), The Fashioned Body, Oxford: Polity.

Entwistle, J. (2015), 'Bruno Latour: Actor-Network-Theory and Fashion', in A. Rocamora and A. Smelik (eds), Thinking Through Fashion, London: IB Tauris, pp.269-84.

Entwistle, J. and Rocamora, A. (2006), 'The Field of Fashion Materialized: A Study of London Fashion Week', Sociology, 40:4,pp.735-51.

Evans, C. and Thornton, M. (1989), Women \& fashion: a new look, London: Quartet.

Foucault, M. (1977), Discipline and Punish: The Birth of the Prison, London: Penguine.

Franks, M. (2000), 'Crossing the Borders of Whiteness? White Muslim Women Who Wear the Hijab in Britain Today’, Ethnic and Racial Studies, 23:5, pp.917-29.

Gilbert, D. (2000), 'Urban Outfitting: The City and the Spaces of Fashion Culture', in S. Bruzzi and P. Church Gibson (eds), Fashion Cultures: Theories, Explorations and Analysis, London: Routledge, pp.7-24.

Gilbert, D. (2006), 'From Paris to Shanghai: The Changing Geographies of Fashion's World Cities', in C. Breward and D. Gilbert (eds), Fashion's World Cities, Oxford: Berg, pp.3-32.

Goffman, E. (1990), The Presentation of Self in Everyday Life, London: Penguin.

Goonewardena, K., Kipfer, S., Milgrom, R. and Schmid. C. (eds) (2008), Space, Difference, Everyday Life: Reading Henri Lefebvre, Oxon: Routledge.

Gramsci, A. (1971), Selections from the Prison Notebooks, London: Lawrence and Wishart. 
Hagemann, A. (2015) 'From Flagship Store to Factory: Tracing the Spaces of Transnational Clothing Production in Istanbul', Articulo - Journal of Urban Research, 12, pp.1-28.

Hamilton, W. (2007), 'Suitably attired: well-dressed men have worn the same thing for a century now - a history and appreciation of the suit', in L. Welters and A. Lillethun (eds), The Fashion Reader, Oxford: Berg, pp.91-94.

Hanson, S. and Pratt, G. (2005), Gender, Work and Space, London: Routledge.

Hollander, A. (1994), Sex and Suits, Knopf.

Hon, L. (2016), 'Social media framing within the Million Hoodies movement for justice', Public Relations Review, 42:1,pp.9-19.

hooks, B. (2003), 'The Oppositional Gaze: Black Female Spectators', in A. Jones (ed.), Feminism and Visual Culture Reader, London: Routledge.

Inglis, D. (2017), 'Cover their face: Masks, masking, and masquerades in historicalanthropological context, in A. Almila and D. Inglis (eds), The Routledge International Handbook to Veils and Veiling Practices, London: Routledge, pp.278-91.

Kinney, A. (2016), Hood, London: Bloomsbury.

Kopytoff, I. (1986), 'The Cultural Biography of Things: Commoditization as Process', in A. Appadurai (ed.), The Social Life of Things: Commodities in Cultural Perspective, Cambridge: Cambridge University Press.

Lefebvre, H. (1991[1974]), The Production of Space, translated by D. Nicholson-Smith, Oxford: Blackwell.

Lewis, R. (ed) (2013), Modest Fashion, London: I.B. Tauris.

Lim, J. and Fanghanel, A. (2013), "'Hijabs, Hoodies and Hotpants": negotiating the "Slut" in SlutWalk', Geoforum, 48,pp.207-15.

Löw, M. (2006), 'The Social Construction of Space and Gender', European Journal of Women's Studies, 13:2,pp.119-133

Lynch, A. (1999) Dress, gender and cultural change: Asian American and African American rites of passage, London: Berg.

Magnet, S. and Rodgers, T. (2012), 'Stripping for the State', Feminist Media Studies, 12:1,pp.101-18.

Masquelier, A. (2005), 'Dirt, Undress, and Difference: An Introduction', in A. Masquelier (ed.), Dirt, Undress, and Difference: Critical Perspectives on the Body's Surface, Bloomington: Indiana University Press.

Massey, D. (2013), Space, Place and Gender, Oxford: Polity.

Moors, A. (2009), 'The Dutch and the Face-Veil: The Politics of Discomfort', Social Anthropology, 17:4,pp.393-408.

Nissen, S. (2008), 'Urban Transformation: From Public and Private Space to Spaces of Hybrid Character', Czech Sociological Review, 44:6,pp.1129-49. 
Paulicelli, E. (2004), Fashion under Fascism, Oxford: Berg.

Pearson, G. (2006), 'Disturbing continuities: "peaky blinders" to "hoodies"', cjm, 65,pp.6-7.

Perkins, C. (2016), 'Mapping and graphicacy', in N. Clifford, M. Cope, T. Gillespie and S. French (eds), Key Methods in Geography, London: Sage, pp.596-619.

Potvin, J. (2009), 'Introduction: Inserting Fashion into Space', in J. Potvin (ed.), The Places and Spaces of Fashion, 1800-2007, London: Routledge, pp.1-15.

Ranade, S. (2007), 'The Way She Moves: Mapping the Everyday Production of GenderSpace', Economic and Political Weekly, 42:17,pp.1519-1526.

Rocamora, A. (2006), 'Paris, Capitale de la Mode: Representing the Fashion City in the Media', in C. Breward and D. Gilbert (eds), Fashion's World Cities, Oxford: Berg.

Rocamora, A. (2013), 'Introduction', in S. Black, A. de la Haye, J. Entwistle, A. Rocamora, R.A. Root and H. Thomas (eds), Handbook of Fashion Studies, London: Bloomsbury, pp.1704.

Rocamora, A. (in press), '\#parisienne: Social Media Stratifications in Visions of Parisian Women'.

Rostam-Kolayi, J. and Matin-Asgari, A. (2014), 'Unveiling Ambiguities: Revisiting 1930s Iran's kashf-i hijab Campaign', in S. Cronin (ed.), Anti-Veiling Campaigns in the Muslim World, London: Routledge, pp.121-48.

Rouse, E. (2007[1989]), 'Why Do People Wear Clothes?', in B. Malcolm (ed.) Fashion Theory: A Reader, London: Routledge.

Said, E. (1994), Culture and Imperialism, London: Vintage.

Schmid, C. (2008), 'Henri Lefebvre's Theory of the Production of Space: Towards a ThreeDimensional Dialectic', in K. Goonewardena, S. Kipfer, R. Milgrom and C. Schmid (eds), Space, Difference, Everyday Life: Reading Henri Lefebvre, Oxon: Routledge.

Secor, A.J. (2002), 'The Veil and Urban Space in Istanbul: Women's dress, mobility and Islamic knowledge', Gender, Place \& Culture, 9:1,pp.5-22.

Simmel, G. (1904), 'Fashion', International Quarterly, 10,pp.130-55.

Soja, E. (1996), Thirdspace, Blackwell.

Soja, E. (2010), Seeking Spatial Justice, University of Minnesota Press.

Speer, A. (1969), Inside the Third Reich, Orion.

Spradley, J.P. (2016), Participant Observation, Illinois: Waveland Press.

Steele, V. (1989), 'Dressing for Work', in C. Brush Kidwell and V. Steele, Men and Women Looking the Part, Smithsonian Institution.

Tarlo, E. (2010), Visibly Muslim, Oxford: Berg.

Welters, L. (2016), 'Introduction', in Welters, L. and Lillethun, A. (eds), The Fashion Reader, Oxford: Berg, pp.233-6. 
Welters, L. and Lillethun, A. (eds) (2007), The Fashion Reader, Oxford: Berg

Welters, L. and Lillethun, A. (eds) (2016), The Fashion Reader, second edition, Oxford: Berg.

Whiteley, N. (2003), 'Intensity of Scrutiny and a Good Eyeful: Architecture and Transparency', Journal of Architectural Education, 56:4,pp.8-16.

Wide, T. (2014), 'Astrakhan, Borqa', Chadari, Dreshi: The Economy of Dress in EarlyTwentieth-Century Afghanistan', in S. Cronin (ed.), Anti-Veiling Campaigns in the Muslim World, London: Routledge.

Woodward, S. (2007), Why Women Wear What They Wear?, Oxford: Berg.

\footnotetext{
${ }^{1}$ The first edition of the Fashion Reader (Welters and Lillethun 2007) featured 'the geography of dress', whereas the second edition (Welters and Lillethun 2016) introduced 'fashion, space and place' (although framed in light of cultural geography or 'new cultural geography' (Welters 2016)). The first edition of Fashion Cultures (Bruzzi and Church Gibson 2000) featured one chapter on space (Gilbert 2000) under 'Shopping, Spaces and Selling'. The section 'Shopping, Spaces and Globalisation' in the second edition (Bruzzi and Church Gibson 2013) was explicitly focussed on fashion cities.

${ }^{2} \mathrm{~A}$ further level of gendered organisation of space, upon which there is no space to elaborate here, is brought in by race, ethnicity and racialization. Black (female) bodies may be marked as 'unprofessional' due to natural hair (Greene 2013), and white female bodies may be racialized by the wearing of garments considered 'Islamic' (Franks 2000). Black bodies may also become highly visible by entering 'white' spaces (hooks 2003).

${ }^{3}$ The suit has of course symbolised numerous things throughout its history, including 'modernisation' and nationbuilding (e.g. Hamilton 2007; Rostam-Kolayi and Matin-asgari 2014; Wide 2014).

4 'Spontaneous' consent, often evoked by appealing myth, is an essential part of the operations of hegemony (Gramsci 1971). This is evident, for example, in the myth of nurturing nature of womanhood and sacrificing motherhood which creates inequal gendered structures of unpaid domestic labour.

5 Lefebvre uses the French expression l'espace de representation. Donald Nicholson-Smith (Lefebvre 1991[1974]) translates this as 'representational spaces', while in the volume Space, Difference, Everyday Life: Reading Henri Lefebvre (Goonewardena et al 2008), 'spaces of representation' is used instead.

${ }^{6}$ As we see in the case of Pussy Riot, this right is not automatically granted for everyone and everywhere - hence the need of resisting bodies.

${ }^{7}$ Along similar lines, Merleau-Ponty (1996[1962]) argues that body and space are inseparable: the human body inhabits space, as opposed to simply being located in it. Consciousness, the movements of the body, and the objects the body aims at through movement, are all spatially intertwined, and, consequently, individual perceptions of the surrounding environment and objects in it are always mediated by the body as well as by the mind. Yet it is not only the individual's mind and body which define how they are to perceive things and objects, but the objects and physical environment themselves have a central role in such perceptions. In a similar vein, it can be argued that 'perception not only takes place in the mind but is based on a concrete, produced materiality' (Schmid 2008: 38, see also Author 2018b).
} 